\title{
PENGARUH FREKUENSI APLIKASI ISOLAT JAMUR ENTOMOPATOGEN Metarhizium anisopliae TERHADAP KUTUDAUN (Aphis glycines Matsumura) DAN ORGANISME NON-TARGET PADA PERTANAMAN KEDELAI
}

\author{
Erna Wathi, Rosma Hasibuan \& Indriyati
}

\author{
Jurusan Agroteknologi, Fakultas Pertanian, Universitas Lampung \\ Jl. Prof. Dr. Soemantri Brodjonegoro, No.1, Bandar Lampung 35145 \\ Emai : erna.wathi@ymail.com
}

\begin{abstract}
ABSTRAK
Penelitian ini bertujuan untuk mengetahui pengaruh frekuensi aplikasi jamur Metarhizium anisopliae terhadap mortalitas dan populasi kutudaun Aphis glycines Matsumura serta populasi organisme nontarget pada pertanaman kedelai. Rancangan percobaan yang digunakan adalah rancangan acak kelompok (RAK) dengan 6 perlakuan dan 3 ulangan. Keenam perlakuan tersebut yaitu tanpa aplikasi (kontrol), 1 kali, 2 kali, 3 kali, 4 kali, dan 5 kali aplikasi M. anisopliae. Data populasi A. glycines, baikyang masih hidup maupun yang telah terinfeksi $M$. anisopliae, serta organisme nontarget diuji dengan sidik ragam dan dilanjutkan dengan Uji Beda Nyata (BNT) dengan taraf nyata 5\%. Hasil penelitian menunjukkan bahwa aplikasiM. anisopliae menyebabkan kematian terhadap kutudaun. Pengamatan langsung terhadap mortalitas A. glycines pada minggu keenam setelah aplikasi menunjukkan bahwa total mortalitas $A$. glycines tertinggi adalah pada frekuensi penyemprotan sebanyak 5 kali. Sedangkan tingkat mortalitas A. glycines tertinggi pada pengamatan dengan teknik ground cloth pada frekuensi penyemprotan M. anisopliae sebanyak 3 kali. Tanaman kedelai yang tidak diaplikasikan jamur M. anisopliae memiliki kepadatan populasi tertinggi dibandingkan tanaman kedelai yang diaplikasikan. Aplikasi $M$. anisopliae dengan berbagai frekuensi berpengaruh nyata terhadap jumlah famili dan total organisme nontarget yang ditemukan pada pitfall trap. Selain itu, aplikasi M. anisopliae tidak berpengaruh terhadap data pendukung berupa tinggi tanaman dan jumlah daun, namun aplikasi jamur berpengaruh nyata pada jumlah bunga, jumlah polong, jumlah polong isi, jumlah polong tidak isi, berat polong kering, dan berat biji kering.
\end{abstract}

Kata kunci : Aphis glycines, frekuensi, Metarhizium anisopliae, mortalitas.

\section{PENDAHULUAN}

Kedelai (Glycine $\max (\mathrm{L})$ Meriill) merupakan salah satu komoditi tanaman yang penting dalam pertanian di Indonesia karena memiliki berbagai manfaat, baik dalam penyediaan pangan, pakan, dan bahan baku industri. Penggunaan kedelai terus meningkat sejalan dengan pertambahan penduduk sehingga produksi nasional tidak dapat memenuhi kebutuhan masyarakat Indonesia. Namun, di sisi lain produksi kedelai di dalam negeri belum mampu mencukupi kenaikan permintaan tersebut (Adisarwanto, 2010).

Menurut Sumarno (2010) produksi kedelai nasional sampai saat ini masih di bawah 2,5 ton/ha. Ada beberapa faktor penyebab penurunan produksi kedelai di Indonesia, salah satunya adalah adanya serangan hama yang dimulai dari awal tanam hingga tanaman siap panen(Rusli, 1999).Pada umumnya, teknik pengendalian yang diterapkan petani dalam mengendalikan $A$. glycines adalah dengan aplikasi pestisida kimia sintetik (Tengkano et al., 2007).
Menurut Kartohardjono (2011), PHT merupakan salah satu metode yang semakin diminati akhir-akhir ini dalam menekan populasi hama. PHT mengelompokan tiga musuh alami dalam tiga kelompok yaitu predator, parasitoid, dan jamur ntomopatogen. Jamur Metarhizium anisopliae merupakan salah satu jamur entomopatogen yang berperan sebagai agen hayati pengendali hama. Peningkatan patogenitas jamur $M$. anisopliae terjadi bila kelembaban udara sangat tinggi hingga $100 \%$. Hal ini karena konidia jamur berkecambah dengan baik. Sementara itu, patogenitas M. anisopliaeakan menurun bila kelembaban udara dibawah 86\% (Prayogo et al., 2005).

Menurut Hall (1973), jamur M. anisopliae memiliki beberapa kelebihan antara lain berkapasitas reproduksi tinggi, relatif aman, siklus hidupnya pendek, selektif, mudah diproduksi, serta dapat bertahan dalam kondisi yang tidak menguntungkan. Jamur patogenik ini dapat menginfeksi beberapa jenis serangga, antara lain serangga yang berasal dari Ordo Coleoptera, Lepidoptera, Hemiptera, dan Isoptera (Prayogo et al., 2005).Pada kondisi tropik di lapang, jamur $M$. 
anisopliae cukup efektif dalam menekan populasi wereng coklat (Suryadi dan Kadir, 2007).

Oleh karena itu, penelitian ini bertujuan untuk mengetahui pengaruh frekuensi aplikasi isolate jamur entomopatogen Metarhizium anisopliae terhadap mortalitas dan populasi Aphis glycines Matsumura serta mengetahui pengaruh frekuensi aplikasi isolate jamur entomopatogen M.iae terhadap populasi musuh alami dan organisme nontarget.

\section{BAHAN DAN METODE}

Penelitian ini dilakukan di Lapangan Terpadu Fakultas Pertanian Universitas Lampung Bandar Lampung mulai dari Bulan Maret sampai Oktober 2014. Alat-alat yang digunakan dalam penelitian ini antara lain kurungan serangga (ukuran kurungan $30 \times 30 \times 80 \mathrm{~cm}$ yang diselimuti kain tile pada sisi samping dan plastik mika pada sisi atas), meteran, ground cloth (kain hampar), pitfall, timbangan elektrik,mikroskop stereo, kaca pembesar (lup), botol film, dan sprayer.Sedangkan bahan-bahan yang digunakan dalam penelitian ini adalah media SDA (Sabouraud Dextrose Agar), isolat jamur M. anisopliae, beras, dan alkohol $70 \%$.

Penelitian ini terdiri atas 6 perlakuan yang diulang sebanyak 3 kali. Keenam perlakuan tersebut yaitu tanpa aplikasi $M$. anisopliae (kontrol), 1 kali aplikasi $M$. anisopliaepada 2 MST, 2 kali aplikasi $M$. anisopliae pada $2 \& 3$ MST, 3 kali aplikasi $M$. anisopliae pada 2 , 3 \& 4 MST, 4 kali aplikasi M. anisopliae pada 2, 3, 4, \& 5 MST, 5 kali aplikasi M. anisopliae pada 2, 3, 4, 5 dan 6 MST.

Pada pembuatan media Sabouraund Dextrose Agar (SDA), komposisi satu liter media terdiri atas 40 g Dextrose, 10 g Pepton, 5 g Kasein, 40 g agar dan 1 liter air destilata (aquades). Semua campuran dimasukkan ke dalam tabung erlenmeyer 1 liter kemudian ditutup dengan alumunium foil. Selanjutnya, larutan SDA disterilisasikan dalam autoclave pada suhu $120^{\circ} \mathrm{C}$ dengan tekanan $1 \mathrm{~atm}$ selama 120 menit. Setelah itu larutan SDA yang sudah steril diangkat dan didiamkan sebentar agar lebih dingin. Kemudian larutan SDA yang sudah dingin dituang ke masing-masing cawan petri (petridish) dalam ruangan steril (Laminar Air Flow).

Pada penyiapan isolat $M$. anisopliae, isolat M.anisopliae yang diaplikasikan di lapang diperbanyak di Universitas Lampung. Selanjutnya, isolat tersebut dipertahankan dan diisolasi dalam Laboratorium Penyakit Jurusan Agroteknologi menggunakan media SDA (Sabouraund Dextrose Agar). Jamur M. anisopliae diperbanyak dengan mencuci beras hingga bersih, kemudian beras tersebut dikukus hingga setengah matang dan didinginanginkan. Beras yang telah dingin $( \pm 100 \mathrm{~g})$ disterilkan dengan autoklaf dengan suhu $120^{\circ} \mathrm{C}$ tekanan $1 \mathrm{~atm}$, selama 120 menit. Jamur M. anisopliae diinokulasikan pada media berasyang telah disterilisasikan, kemudian media beras tersebut diinkubasi selama 2 minggu. Setelah itu, biakan $M$. anisopliae yang telah siap pakai ditimbang sebanyak 100 gram dan diblender hingga halus.

Pada pembuatan Formulasi Kering $M$. anisopliae, langkah pertama adalah dimulai dengan mengeringkan media beras yang telah ditumbuhi $M$. anisopliaeberumur 2 minggu ke dalam lemari pendingin pada suhu $5^{\circ} \mathrm{C}$ selama 12 hari. Langkah selanjutnya, $M$. anisopliae yang telah kering diblender hingga halus dan diayak untuk mendapatkan tepung biomassa spora. Bahan pembawa seperti zeolit, kaolin, dan tepung jagung disterilisasikan terlebih dahulu.Komposisi tepung biomassa spora dan bahan pembawa tersebut adalah: $40 \mathrm{~g}$ tepung biomassa spora, $20 \mathrm{~g}$ kaolin, $20 \mathrm{~g}$ zeolit, dan $20 \mathrm{~g}$ tepung jagung untuk menghasilkan formulasi kering sebanyak $100 \mathrm{~g}$. Pembuatan formulasi kering ini mengacu pada penelitian Punomo dkk (2012).

Pada pelaksanaan penelitian aplikasi $M$. anisopliae, aplikasi dilakukan pada sore hari terhadap seluruh tanaman dengan menggunakan backpack sprayer. Penyemprotan dilakukan dengan konsentrasi 20 gram formulasi kering $M$. anisopliae per liter air. Aplikasi pertama dilakukan terhadap semua plot percobaan pada saat tanaman kedelai berumur 2 minggu setelah tanam (MST), sedangkan penyemprotan kedua dilakukan untuk plot perlakuan $\mathrm{F}_{2}, \mathrm{~F}_{3}, \mathrm{~F}_{4}$, dan $\mathrm{F}_{5}$ pada saat tanaman berumur 3 MST. Penyemprotan ketiga dilakukan pada plot perlakuan $\mathrm{F}_{3}, \mathrm{~F}_{4}$, dan $\mathrm{F}_{5}$ pada saat tanaman berumur 4 MST. Penyemprotan keempat dilakukan pada plot perlakuan $\mathrm{F}_{4}$ dan $\mathrm{F}_{5}$ pada saat tanaman berumur 5 MST. Sedangkan penyemprotan kelima dilakukan pada plot perlakuan $\mathrm{F}_{5}$ pada saat tanaman berumur 6 MST.

Pada pengamatan langsung populasi kutu Aphis glycines secara langsung dilakukandengan menghitung seluruh jumlah kutu yang tidak terinfeksi jamur $M$. anisopliae pada tanaman kedelai. Populasi A. glycines menggunakan kaca pembesar (lup) dan hand colony counter.Pengamatan dilakukan setiap hari yang dimulai dari 1 hingga 7 hari setelah aplikasi. Pada pengamatan mortalitas kutu Aphis glycines dengan teknik ground cloth, sebelum diaplikasikan M. anisopliae, kain hampar (ground cloth) diletakkan tepat di bawah tanaman kedelai pada sore hari. Pengamatan dilakukan setiap hari hingga 7 hari setelah aplikasi. Setelah tanaman disemprot, kain hampar diperiksa untuk diketahui jumlah kutu mati yang terinfeksi jamur $M$. 
anisopliae. Setelah itu, kutu yang telah dikumpulkan selanjutnya diidentifikasi di Laboratorium Hama Tanaman Fakultas Pertanian Universitas Lampung.

Pada pengamatan organisme nontarget dengan teknik pitfall, Pitfall dipasang pada sore hari sebelum aplikasi M. anisopliae pada tanaman sampel. Pada tiap plot percobaan diletakkan 2 buah pitfall sehingga terdapat 36pitfall. Setelah 24 jam, pitfall diambil dan dibawa ke Laboratorium Hama Jurusan Agroteknologi untuk perhitungan dan diidentifikasi organisme yang terjebak dalam pitfall.

Data penunjang pada penelitian ini didapat dari pengamatan variabel tanaman. Variabel yang diamati terbagi menjadi 3 yaitu variabel vegetatif, variabel generatif, serta pengamatan pascapanen. Variabel vegetatif meliputi tinggi tanaman dan jumlah daun kedelai. Variabel generatif meliputi jumlah bunga dan jumlah polong Sedangkan pengamatan pascapanen meliputi berat brangkasan basah dan berat brangkasan kering tanaman kedelai.

\section{HASIL DAN PEMBAHASAN}

Pengamatan langsung terhadap mortalitas yang diduga terinfeksi oleh $M$. anisopliae dilakukan saat tanaman berumur 2 MST hingga 6 MST. Total rerata mortalitas kutu pada Tabel 1 menunjukkan bahwa frekuensi penyemprotan $M$. anisopliae berpengaruh nyata terhadap mortalitas kutu. Namun, pada pengamatan hari pertama, keempat, keenam dan ketujuh setelah aplikasi terilihat bahwa frekuensi aplikai jamur tidak berpengaruh nyata terhadap mortalitas kutudaun. Pengamatan hari kedua setelah aplikasi sudah mampu menyebabkan mortalitas kutudaun. Hal ini karena konidia jamurpada pengamatan hari pertama belum dapat menginfeksi A. glycines (Prayogo, 2006). Rendahnya jumlah mortalitas kutudaun pada tanaman kedelai berumur 6 MST ini diduga karena umur biakan jamur yang telah melebihi 1 bulan sehingga nutrisi dalam media banyak digunakan untuk membentuk struktur khusus yaitu arthospora. Hal ini mengakibatkan

Tabel 1. Rata-rata kutudaun A. glycines (ekor/rumpun tanaman) yang terinfeksi jamur M. anisopliae pada 6 MST dengan pengamatan langsung.

\begin{tabular}{cclllllll}
\hline & \multicolumn{7}{c}{ Pengamatan Hari ke- } \\
\cline { 2 - 8 } Perlakuan & 1 HSA & 2 HSA & 3 HSA & 4 HSA & 5 HSA & 6 HSA & 7 HSA & Total \\
\hline F0 & $0,67 \mathrm{a}$ & $0,33 \mathrm{c}$ & $0,33 \mathrm{c}$ & $1,00 \mathrm{~b}$ & $0,33 \mathrm{bc}$ & $0,00 \mathrm{a}$ & $0,00 \mathrm{a}$ & $2,67 \mathrm{e}$ \\
F1 & $0,67 \mathrm{a}$ & $1,33 \mathrm{ab}$ & $1,00 \mathrm{bc}$ & $1,00 \mathrm{~b}$ & $0,00 \mathrm{c}$ & $0,00 \mathrm{a}$ & $0,33 \mathrm{a}$ & $4,33 \mathrm{~d}$ \\
F2 & $0,67 \mathrm{a}$ & $1,00 \mathrm{bc}$ & $1,67 \mathrm{ab}$ & $1,67 \mathrm{ab}$ & $0,67 \mathrm{~b}$ & $0,00 \mathrm{a}$ & $0,00 \mathrm{a}$ & $5,67 \mathrm{c}$ \\
F3 & $0,67 \mathrm{a}$ & $1,33 \mathrm{ab}$ & $1,67 \mathrm{ab}$ & $2,33 \mathrm{a}$ & $1,33 \mathrm{a}$ & $0,00 \mathrm{a}$ & $0,00 \mathrm{a}$ & $7,33 \mathrm{~b}$ \\
F4 & $1,00 \mathrm{a}$ & $1,33 \mathrm{ab}$ & $2,33 \mathrm{a}$ & $2,00 \mathrm{a}$ & $0,67 \mathrm{~b}$ & $0,00 \mathrm{a}$ & $0,00 \mathrm{a}$ & $7,33 \mathrm{~b}$ \\
F5 & $1,00 \mathrm{a}$ & $2,00 \mathrm{a}$ & $2,33 \mathrm{a}$ & $2,00 \mathrm{a}$ & $0,67 \mathrm{~b}$ & $0,33 \mathrm{a}$ & $0,33 \mathrm{a}$ & $8,67 \mathrm{a}$ \\
\hline Pr>F & 0,8723 & 0,0442 & 0,0006 & 0,0597 & 0,0167 & 0,4651 & 0,6187 & 0,0000 \\
\hline
\end{tabular}

Keterangan : Nilai sekolom yang diikuti huruf yang sama berarti tidak berbeda nyata pada Uji BNT taraf nyata 5\%; HSA: hari setelah aplikasi.

Tabel 2. Jumlah mortalitas kutudaun $A$. glycines (ekor/rumpun tanaman) pada 6 MST dengan teknik pengamatan ground cloth.

\begin{tabular}{cclllllll}
\hline & \multicolumn{7}{c}{ Pengamatan Hari ke- } \\
\cline { 2 - 8 } Perlakuan & 1 HSA & 2 HSA & 3 HSA & 4 HSA & 5 HSA & 6 HSA & 7 HSA & Total \\
\hline F0 & $0,00 \mathrm{~b}$ & $0,33 \mathrm{~b}$ & $1,33 \mathrm{~b}$ & $1,33 \mathrm{~b}$ & $1,00 \mathrm{~b}$ & $1,00 \mathrm{~b}$ & $0,67 \mathrm{a}$ & $5,67 \mathrm{c}$ \\
F1 & $0,00 \mathrm{~b}$ & $0,33 \mathrm{~b}$ & $1,33 \mathrm{~b}$ & $2,67 \mathrm{a}$ & $2,33 \mathrm{ab}$ & $1,67 \mathrm{ab}$ & $1,33 \mathrm{a}$ & $9,67 \mathrm{bc}$ \\
F2 & $0,33 \mathrm{ab}$ & $2,00 \mathrm{a}$ & $2,33 \mathrm{ab}$ & $2,67 \mathrm{a}$ & $2,33 \mathrm{ab}$ & $2,00 \mathrm{ab}$ & $1,33 \mathrm{a}$ & $13,00 \mathrm{ab}$ \\
F3 & $0,67 \mathrm{ab}$ & $2,33 \mathrm{a}$ & $3,33 \mathrm{a}$ & $3,67 \mathrm{a}$ & $3,00 \mathrm{a}$ & $2,33 \mathrm{ab}$ & $2,00 \mathrm{a}$ & $17,33 \mathrm{a}$ \\
F4 & $0,67 \mathrm{ab}$ & $1,67 \mathrm{ab}$ & $2,33 \mathrm{ab}$ & $3,67 \mathrm{a}$ & $3,00 \mathrm{a}$ & $2,67 \mathrm{a}$ & $1,67 \mathrm{a}$ & $15,67 \mathrm{ab}$ \\
F5 & $1,00 \mathrm{a}$ & $1,67 \mathrm{ab}$ & $2,67 \mathrm{a}$ & $3,00 \mathrm{a}$ & $2,00 \mathrm{ab}$ & $2,00 \mathrm{ab}$ & $1,33 \mathrm{a}$ & $13,67 \mathrm{ab}$ \\
\hline Pr>F & 0,0297 & 0,0367 & 0,0183 & 0,0037 & 0,0315 & 0,1606 & 0,6602 & 0,0099 \\
\hline
\end{tabular}

Keterangan : Nilai sekolom yang diikuti huruf yang sama berarti tidak berbeda nyata pada Uji BNT taraf nyata 5\%; HSA: hari setelah aplikasi. 
Tabel 3. Rata-rata populasi kutudaun A. glycines (ekor/ tanaman) pada 6 MST dengan teknik pengamatan langsung

\begin{tabular}{cclllllll}
\hline & \multicolumn{7}{c}{ Pengamatan Hari ke- } \\
\cline { 2 - 8 } Perlakuan & 1 HSA & 2 HSA & 3 HSA & 4 HSA & 5 HSA & 6 HSA & 7 HSA & Total \\
\hline F0 & $27,67 \mathrm{ab}$ & $26,94 \mathrm{ab}$ & $26,62 \mathrm{a}$ & $26,01 \mathrm{a}$ & $25,28 \mathrm{a}$ & $27,72 \mathrm{a}$ & $28,50 \mathrm{a}$ & $188,78 \mathrm{a}$ \\
F1 & $27,56 \mathrm{ab}$ & $27,22 \mathrm{a}$ & $26,22 \mathrm{a}$ & $25,67 \mathrm{a}$ & $24,78 \mathrm{a}$ & $27,56 \mathrm{a}$ & $28,44 \mathrm{a}$ & $187,39 \mathrm{a}$ \\
F2 & $27,56 \mathrm{ab}$ & $26,67 \mathrm{ab}$ & $26,11 \mathrm{a}$ & $25,17 \mathrm{a}$ & $24,44 \mathrm{a}$ & $27,00 \mathrm{a}$ & $26,89 \mathrm{a}$ & $183,89 \mathrm{~b}$ \\
F3 & $26,94 \mathrm{~b}$ & $26,28 \mathrm{~b}$ & $26,17 \mathrm{a}$ & $25,28 \mathrm{a}$ & $24,72 \mathrm{a}$ & $27,11 \mathrm{a}$ & $28,22 \mathrm{a}$ & $184,72 \mathrm{~b}$ \\
F4 & $27,78 \mathrm{ab}$ & $26,89 \mathrm{ab}$ & $26,39 \mathrm{a}$ & $25,89 \mathrm{a}$ & $25,17 \mathrm{a}$ & $27,83 \mathrm{a}$ & $28,28 \mathrm{a}$ & $188,22 \mathrm{a}$ \\
F5 & $28,11 \mathrm{a}$ & $27,44 \mathrm{a}$ & $26,22 \mathrm{a}$ & $25,44 \mathrm{a}$ & $25,28 \mathrm{a}$ & $27,61 \mathrm{a}$ & $28,56 \mathrm{a}$ & $188,56 \mathrm{a}$ \\
\hline Pr>F & 0,2649 & 0,0956 & 0,6472 & 0,3018 & 0,7557 & 0,3353 & 0,1307 & 0,0014 \\
\hline
\end{tabular}

Keterangan : Nilai sekolom yang diikuti huruf yang sama berarti tidak berbeda nyata pada Uji BNT taraf nyata 5\%; HSA: hari setelah aplikasi.

Tabel 4. Jumlah famili dan organisme nontarget yang ditemukan pada pitfall trap selama 7 kali pengamatan.

\begin{tabular}{ccc}
\hline & \multicolumn{2}{c}{ Organisme Nontarget Pada Pitfall Trap } \\
\cline { 2 - 3 } Perlakuan & Jumlah Famili & Total Organisme \\
\hline F0 & $5,00 \mathrm{~b}$ & $208,33 \mathrm{a}$ \\
F1 & $6,67 \mathrm{a}$ & $185,67 \mathrm{ab}$ \\
F2 & $4,00 \mathrm{~b}$ & $181,00 \mathrm{~b}$ \\
F3 & $6,67 \mathrm{a}$ & $187,00 \mathrm{~b}$ \\
F4 & $6,67 \mathrm{a}$ & $181,33 \mathrm{~b}$ \\
F5 & $4,00 \mathrm{~b}$ & $185,67 \mathrm{ab}$ \\
\hline Pr $>$ F & 0,0003 & 0,2560 \\
\hline
\end{tabular}

Keterangan : Nilai sekolom yang diikuti huruf yang sama berarti tidak berbeda nyata pada Uji BNT taraf nyata $5 \%$; HSA: hari setelah aplikasi.

Table 5. Kepadatan populasi organisme nontarget mayor pada pitfall trapsaat aplikasi jamur $M$. anisopliae.

\begin{tabular}{ccccc}
\hline & \multicolumn{4}{c}{ Organisme Nontarget Pada Pitfall Trap } \\
\cline { 2 - 5 } Perlakuan & Formicidae & Gryllidae & Lycosidae & Artropoda minor \\
\hline F0 & $43,00 \mathrm{a}$ & $24,33 \mathrm{a}$ & $69,33 \mathrm{a}$ & $45,00 \mathrm{a}$ \\
F1 & $41,67 \mathrm{a}$ & $24,33 \mathrm{a}$ & $68,00 \mathrm{a}$ & $51,67 \mathrm{a}$ \\
F2 & $41,33 \mathrm{a}$ & $25,67 \mathrm{a}$ & $69,00 \mathrm{a}$ & $45,00 \mathrm{a}$ \\
F3 & $42,33 \mathrm{a}$ & $21,00 \mathrm{a}$ & $65,33 \mathrm{a}$ & $58,33 \mathrm{a}$ \\
F4 & $44,33 \mathrm{a}$ & $25,33 \mathrm{a}$ & $71,67 \mathrm{a}$ & $51,67 \mathrm{a}$ \\
F5 & $43,33 \mathrm{a}$ & $24,33 \mathrm{a}$ & $69,67 \mathrm{a}$ & $48,33 \mathrm{a}$ \\
\hline Pr>F & 0,9108 & 0,8545 & 0,8273 & 0,0767 \\
\hline
\end{tabular}

Keterangan : Nilai sekolom yang diikuti huruf yang sama berarti tidak berbeda nyata pada Uji BNT taraf nyata 5\%; HSA: hari setelah aplikasi.

beberapa organ khusus tidak efektif lagi bila digunakan sebagai organ infektif dalam mengendalikan hama sasaran (Prayogo, 2005). Data pada Tabel 2 menunjukkan bahwa total rerata $A$. glycines yang diamati dengan teknik ground cloth berbeda nyata antarperlakuan. Selain itu, hal yang sama juga terjadi pada pengamatan hari ke-1 hingga ke-5 setelah aplikasi yang menunjukkan pengaruh nyata penyemrotan $M$. anisopliae terhadap mortalitas $A$. glycines. Kututdaun A. glycines yang terjatuh pada ground cloth tidak semuanya terinfeksi oleh jamur $M$. anisopliae, melainkan sebagian diduga karena faktor umur. Hal ini 
Tabel 6. Data pengamatan brangkasan kering tanaman kedelai.

\begin{tabular}{ccccc}
\hline & \multicolumn{4}{c}{ Pengamatan } \\
\cline { 2 - 5 } Perlakuan & $\begin{array}{c}\text { Berat } \\
\text { Brangkasan } \\
\text { Kering (gram) }\end{array}$ & $\begin{array}{c}\text { Berat Brangkasan } \\
\text { Tanpa Polong } \\
\text { (gram) }\end{array}$ & $\begin{array}{c}\text { Berat Polong } \\
\text { Kering }\end{array}$ & $\begin{array}{c}\text { Berat } \\
\text { Biji Kering }\end{array}$ \\
\hline F0 & $49,94 \mathrm{a}$ & $37,98 \mathrm{a}$ & $11,96 \mathrm{~b}$ & $7,81 \mathrm{~b}$ \\
F1 & $79,96 \mathrm{a}$ & $57,90 \mathrm{a}$ & $21,29 \mathrm{ab}$ & $10,72 \mathrm{~b}$ \\
F2 & $91,10 \mathrm{a}$ & $61,15 \mathrm{a}$ & $29,95 \mathrm{ab}$ & $18,97 \mathrm{a}$ \\
F3 & $98,99 \mathrm{a}$ & $67,01 \mathrm{a}$ & $33,99 \mathrm{a}$ & $19,90 \mathrm{a}$ \\
F4 & $65,33 \mathrm{a}$ & $55,76 \mathrm{a}$ & $20,77 \mathrm{ab}$ & $19,46 \mathrm{a}$ \\
F5 & $79,59 \mathrm{a}$ & $56,55 \mathrm{a}$ & $23,04 \mathrm{ab}$ & $11,86 \mathrm{~b}$ \\
\hline Pr>F & 0,4819 & 0,8380 & 0,2598 & 0,0651 \\
\hline
\end{tabular}

Keterangan : Nilai sekolom yang diikuti huruf yang sama berarti tidak berbeda nyata pada Uji BNT taraf nyata $5 \%$; HSA: hari setelah aplikasi.

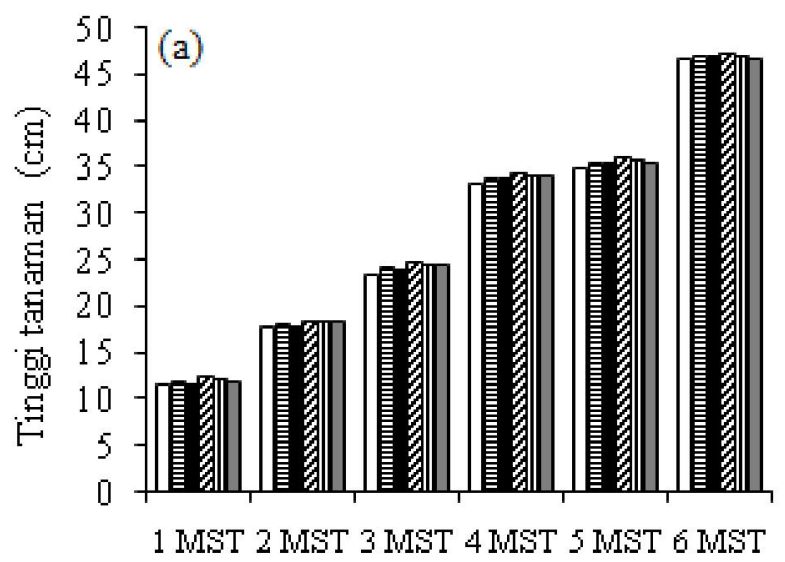

Waktu pengamatan

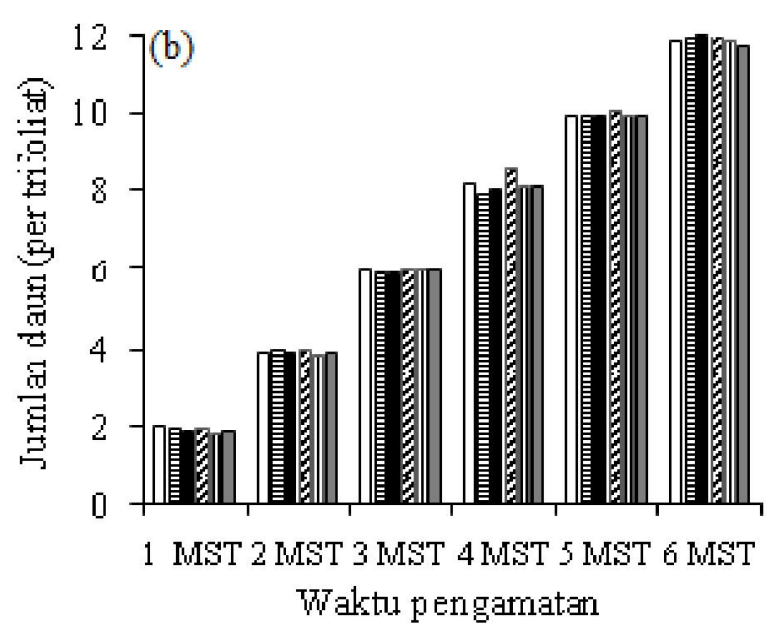

Gambar 1. (a) Grafik rata-rata tinggi tanaman kedelai selama 6 minggu pengamatan dan hasil analisis sidik ragam adalah $\operatorname{Pr}>\mathrm{F}=0,0005$; (b) Grafik rata-rata jumlah daun tanaman kedelai selama 6 minggu pengamatan dan hasil analisis sidik ragam adalah $\operatorname{Pr}>\mathrm{F}=0$, 6504. F0 ( $\square)=$ kontrol; F1 (目) = frekuensi aplikasi jamur M. anisopliae 1 kali; F2 (ם) = frekuensi aplikasi jamur M. anisopliae 2 kali; F3 (ש) $=$ frekuensi aplikasi jamur M. anisopliae 3 kali; F4 (四) = frekuensi aplikasi jamur M. anisopliae 4 kali; F5 (口) = frekuensi aplikasi jamur M. anisopliae 5 kali.

disebabkan karena $A$. glycines yang terdapat pada pertanaman kedelai memiliki umur yang tidak seragam. Selain itu, faktor lingkungan juga menjadi penyebab kematian A. glycines.

Hasil penelitian menunjukkan bahwa aplikasi jamur M. anisopliae secara umum berpengaruh terhadap kepadatan populasi kutu $A$. glycines. Berbanding terbalik dengan pengamatan mortalitas kutu yang mengalami peningkatan pada minggu kedua dan ketiga setelah tanam, populasi kutu semakin menurun pada minggu tersebut. Selanjutnya, pada minggu kedua aplikasi atau saat tanaman berumur 3 MST, populasi meningkat pada hari ke-2 setelah aplikasi. Penurunan tingkat virulensi jamur juga terjadi pada saat tanaman berumur 5 MST dimana perlakuan F2 dan F3 nyata lebih tinggi dibandingkan perlakuan F0, F1, F4, dan F5. Pada pengamatan tanaman kedelai berumur $6 \mathrm{MST}$, aplikasi jamur M. anisopliae sebanyak 5 kali baru dilaksanakan. Data total kutu A. glycines pada Tabel 3 menunjukkan bahwa aplikasi $M$. anisopliae berpengaruh nyata terhadap kepadatan populasi $A$. glycines. Namun, pada setiap hari pengamatanmenunjukkan bahwa aplikasi $M$. anisopliae tidak berpengaruh nyata terhadap populasi kutu pada tanaman kedelai di lapang. 

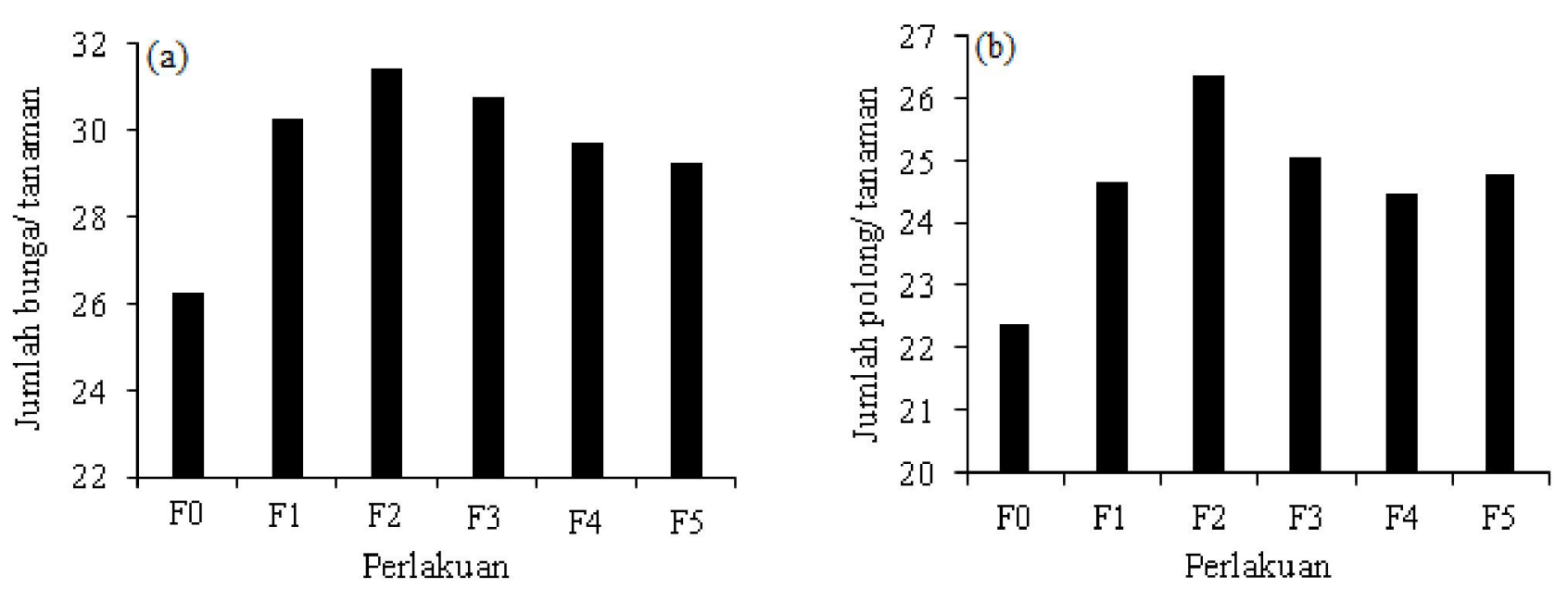

Gambar 2. (a) Grafik rata-rata jumlah bunga tanaman kedelai pada pengamatan 5 MST; (b) Grafik rata-rata jumlah polong tanaman kedelai pada pengamatan $6 \mathrm{MST}$. F0 $=$ kontrol; F1 $=$ frekuensi aplikasi jamur M. anisopliae 1 kali; F2 = frekuensi aplikasi jamur M. anisopliae 2 kali; F3 = frekuensi aplikasi jamur M. anisopliae 3 kali; F4 = frekuensi aplikasi jamur M. anisopliae 4 kali; F5 = frekuensi aplikasi jamur M. anisopliae 5 kali.

Dilihat dari jumlah famili dan total organisme yang ada pada pertanaman kedelai menunjukkan bahwa aplikasi formulasi kering jamur $M$. anisopliae mempengaruhi total organisme yang berasosiasi dengan tanaman kedelai dan jumlah famili yang ditemukan pada pitfall trap. Selama pengamatan terdapat 3 famili dominan yang ditemukan yaitu Formicidae, Gryllidae, dan Lycosidae. Ketiga famili tersebut berperan sebagai musuh alami $A$. glycines (Tabel 4 dan Tabel 5).

Setelah dilakukan 6 minggu pengamatan, aplikasi $M$. anisopliae berpengaruh nyata terhadap tinggi tanaman, namun tidak berpengaruh nyata terhadap jumlah daun tanaman kedelai. Hasil analisis sidik ragam untuk tinggi tanaman kedelai adalah 0,0005 , sedangkan untuk jumlah daun tanaman kedelai adalah 0,6504 (Gambar 1a dan Gambar 1b).

Berdasarkan Gambar 2a dan Gambar 2b diketahui bahwa aplikasi jamur $M$. anisopliae berpengaruh terhadap jumlah bunga dan jumlah polong tanaman kedelai. Perlakuan F2 dengan aplikasi $M$. anisopliae sebanyak 2 kali mampu meningkatkan jumlah bunga dan jumlah polong kedelai.

Dari data yang diperoleh pada Tabel 6, aplikasi M. anisopliae tidak berpengaruh nyata terhadap berat brangkasan basah, berat brangkasan tanpa polong, berat brangkasan kering dan berat brangkasan kering tanpa polong. Namun, aplikasi $M$. anisopliae berpengaruh terhadap jumlah bunga, jumlah polong, jumlah polong isi, jumlah polong tidak berisi, berat polong kering, dan berat biji kering.

\section{KESIMPULAN}

Kesimpulan yang dapat diperoleh dari penelitian ini adalah aplikasi isolat jamur Metarhizium anisopliae mampu menginfeksi dan menyebabkan kematian terhadap hama kutudaun Aphis glycines di pertanaman kedelai. Aplikasi M. anisopliae dengan berbagai frekuensi berpengaruh nyata terhadap jumlah famili organisme nontarget dan total organisme nontarget yang terjebak dalam pitfall trap. Secara umum frekuensi aplikasi $M$. anisopliae tidak mempengaruhi data pendukung berupa tinggi tanaman dan jumlah daun, namun penyemprotan $M$. anisopliae berpengaruh nyata terhadap jumlah bunga, jumlah polong, jumlah polong isi, polong tidak isi, berat polong kering, dan berat biji kering.

\section{DAFTAR PUSTAKA}

Adisarwanto, T. 2010. Strategi peningkatan produksi kedelai sebagai upaya untuk memenuhi kebutuhan di dalam negeri dan mengurangi impor. Pengembangan Inovasi Pertanian 3(4) 319-331. 
Hall, T.M. 1973. Use of microorganisms in biological control. p. 610"628. In P. Debach, (Ed.). Biological Control of Insects Pest and Weeds. Chapman and Hall Ltd., London.

Kartohardjono, A. 2011. Penggunaan musuh alami sebagai komponen pengendalian hama padi berbasis ekologi. Pengembangan Inovasi Pertanian 4 (1): 29-46.

Prayogo, Y., Tengkano, W., \& Marwoto. 2005.Prospek Cendawan Entomopatogen Metarhizium anisopliae Untuk Mengendalikan Ulat Grayak Spodoptera Litura Pada Kedelai. J. Litbang Pertanian. 24(1):19-26.

Prayogo, Y. 2006. Upaya Mempertahankan Keefektifan Cendawan Entomopatogen untuk mengendalikan Hama Tanaman Pangan. J. Litbang Pertanian. 25(2):47-54.

Purnomo, Aeny, T.N., \& Fitriana, Y. 2012. Pembuatan dan Aplikasi Formulasi Kering Tiga Jenis Agensia
Hayati untuk Mengendalikan Hama Pencucuk Buah dan Penyakit Buah Kakao. Laporan Penelitian Hibah Bersaing. Bandar Lampung.

Rusli, R. 1999. Biologi Aphis glycines Matsumura (Homophera: Aphididae) Pada Beberapa Tingkat Umur Tanaman Kedelai (Glycine max (L) Merrill). Jurnal Natur Indonesia I1 (1) : 80-84 (1999).

Sumarno. 2010. Pemanfaatan teknologi genetika untuk peningkatan produksi kedelai. Pengembangan Inovasi pertanian 3(4): 247-259.

Suryadi, Y.\& Kadir, T. S. 2007. Pengamatan Infeksi Jamur Patogen Serangga Metarhizium anisopliae (Metsch, Sorokin) pada Wereng Coklat. Berita Biologi 8(6):501-507.

Tengkano, Supriyatin, Suharsono, Bedjo, Yusmani P., \& Purwantoro. 2007. Status Hama Kedelai dan Musuh Alami pada Lahan Kering Masam Lampung. J. Litbang Pertanian 29(1): 1-9. 